DOI: $10.17516 / 1997-1397-2020-13-2-213-217$

УДК 539.374

\title{
Anisotropic Antiplane Elastoplastic Problem
}

\author{
Sergei I. Senashov* \\ Irina L. Savostyanova ${ }^{\dagger}$ \\ Reshetnev Siberian State University of Science and Technology \\ Russian Federation \\ Olga N. Cherepanova $a^{\ddagger}$ \\ Siberian Federal University \\ Krasnoyarsk, Russian Federation
}

Received 10.11.2019, received in revised form 11.01.2020, accepted 20.02.2020

\begin{abstract}
In this work we solve an anisotropic antiplane elastoplastic problem about stress state in a body weakened by a hole bounded by a piecewise-smooth contour. We give the conservation laws which allowed us to reduce calculations of stress components to a contour integral over the contour of the hole. The conservation laws allowed us to find the boundary between the elastic and plastic areas.
\end{abstract}

Keywords: anisotropic elastoplastic problem, antiplane stress state, conservation laws.

Citation: S.I.Senashov, I.L.Savostyanova, O.N.Cherepanova, Anisotropic Antiplane Elastoplastic Problem, J. Sib. Fed. Univ. Math. Phys., 2020, 13(2), 213-217.

DOI: $10.17516 / 1997-1397-2020-13-2-213-217$.

\section{Introduction}

Fields of shifts and stresses in the case under consideration are the following [1]

$$
u=v=0, \quad w=w(x, y) \quad \sigma_{x}=\sigma_{y}=\sigma_{z}=\tau_{x y}=0, \quad \tau_{x z}=\tau^{1}(x, y), \quad \tau_{y z}=\tau^{2}(x, y) .
$$

Here $u, v, w$ are shift vector components, $\sigma_{x}, \sigma_{y}, \sigma_{z}, \tau_{x y}, \tau_{x z}, \tau_{y z}$ are stress components, $x, y, z$ the Cartesian coordinates, axis directed parallel to the element.

In the elastic zone there are the relations

$$
\begin{gathered}
\left.\frac{\partial \tau^{1}}{\partial x}+\frac{\partial \tau^{2}}{\partial y}=0 \text { (equilibrium equation }\right) \\
\tau^{1}=\frac{\partial w}{\partial x}, \tau^{2}=G_{2} \frac{\partial w}{\partial y}(\text { Hooke's law }) .^{\prime} .
\end{gathered}
$$

Here $G_{i}$ are constants called elastic moduli [2].

From (2), (3) there arise relations in the elastic zone

$$
\begin{gathered}
G_{1} \frac{\partial^{2} w}{\partial x^{2}}+G_{2} \frac{\partial^{2} w}{\partial y^{2}}=0, \\
G_{2} \frac{\partial \tau^{1}}{\partial y}=G_{1} \frac{\partial \tau^{2}}{\partial x} .
\end{gathered}
$$

*sen@mail.sibsau.ru https://orcid.org/0000-0001-5542-4781

${ }^{\dagger}$ ruppa@inbox.ru https://orcid.org/0000-0002-9675-7109

${ }^{\ddagger}$ cheronik@mail.ru

(c) Siberian Federal University. All rights reserved 
From (2) and (5) it follows that $\tau^{1}, \tau^{2}$ satisfy the system of linear equations

$$
F_{1}=\frac{\partial \tau^{1}}{\partial x}+\frac{\partial \tau^{2}}{\partial y}=0, \quad F_{2}=\frac{\partial \tau^{1}}{\partial y}-n \frac{\partial \tau^{2}}{\partial x}=0
$$

where $n=G_{1} / G_{2}$.

In the plastic zone there holds the relation (2), and also

$$
\begin{gathered}
a_{13}\left(\tau^{1}\right)^{2}+a_{23}\left(\tau^{2}\right)^{2}=1 \text { (yield condition) } \\
\tau^{2} \frac{\partial w}{\partial x}=\tau^{1} \frac{\partial w}{\partial y}(\text { Hencky's equation }) .
\end{gathered}
$$

Here $a_{13}, a_{23}$ are constants called anisotropy coefficients.

On the boundary of the elastic and plastic areas the stresses and shifts are supposed to be continuous.

\section{Conservation laws}

By a conservation law for the system of equations (6) we shall call the relation of the form of

$$
\frac{\partial A\left(x, y, \tau^{1}, \tau^{2}\right)}{\partial x}+\frac{\partial B\left(x, y, \tau^{1}, \tau^{2}\right)}{\partial y}=\omega^{1} F_{1}+\omega^{2} F_{2},
$$

where $\omega^{i}=\omega^{i}\left(x, y, \tau^{1}, \tau^{2}\right)$ are some functions not identically zero simultaneously.

Note. A more general definition of conservation laws and their use in mechanics of a solid body being deformed can be studied for example in [3-5].

For the purposes that are set in this article a simplified formulation in the form of (9) will suit fine.

In (9) the values $A, B$ are called conserved current components.

Let us assume that the components $A, B$ appear as follows

$$
A=\alpha^{1} \tau^{1}+\beta^{1} \tau^{2}+\gamma^{1}, \quad B=\alpha^{2} \tau^{1}+\beta^{2} \tau^{2}+\gamma^{2},
$$

where $\alpha^{i}=\alpha^{i}(x, y), \beta^{i}=\beta^{i}(x, y), \gamma^{i}=\gamma^{i}(x, y)$ are some smooth functions to be determined.

Let us substitute (10) into (9), as a result we obtain

$$
\begin{aligned}
& \alpha_{x}^{1} \tau^{1}+\alpha^{1} \tau_{x}^{1}+\beta_{x}^{1} \tau^{2}+\beta^{1} \tau_{x}^{2}+\gamma_{x}^{1}+\alpha_{y}^{2} \tau^{1}+\alpha^{2} \tau_{y}^{1}+\beta_{y}^{2} \tau^{2}+\beta^{2} \tau_{y}^{2}+\gamma_{y}^{2}= \\
& =\omega^{1}\left(\tau_{x}^{1}+\tau_{y}^{2}\right)+\omega^{2}\left(\tau_{y}^{1}-n \tau_{x}^{2}\right)=0,
\end{aligned}
$$

where the index below stands for a derivative with respect to the corresponding variable.

From (11) we obtain

$$
\alpha^{1}=\omega^{1}, \quad \beta^{1}=-n \omega^{2}, \quad \alpha^{2}=\omega^{2}, \quad \beta^{2}=\omega^{1}, \quad \alpha_{x}^{1}+\alpha_{y}^{2}=0, \quad \beta_{x}^{1}+\beta_{y}^{2}=0, \quad \gamma_{x}^{1}+\gamma_{y}^{2}=0 .
$$

From (12) excluding $\omega^{i}$ we obtain

$$
\alpha^{1}=\beta^{2}, \quad \beta^{1}=-n \alpha^{2}, \quad \alpha_{x}^{1}-n \beta_{y}^{1}=0, \quad \beta_{x}^{1}+\alpha_{y}^{1}=0, \quad \gamma_{x}^{1}+\gamma_{y}^{2}=0 .
$$

By virtue of relations (12) the conserved current components are written as

$$
A=\alpha^{1} \tau^{1}+\beta^{1} \tau^{2}+\gamma^{1}, \quad B=\frac{-\beta^{1}}{n} \tau^{1}+\alpha^{1} \tau^{2}+\gamma^{2}
$$


Since the right-hand part (9) is equal to zero, according to Green's formula we obtain

$$
\begin{aligned}
& \iint_{S}\left(A_{x}+B_{y}\right) d x d y=\oint_{\partial S} A d y-B d x= \\
& =\oint_{\partial S}\left(\alpha^{1} \tau^{1}+\beta^{1} \tau^{2}+\gamma^{1}\right) d y-\left(\frac{-\beta^{1}}{n} \tau^{1}+\alpha^{1} \tau^{2}+\gamma^{2}\right) d x=0,
\end{aligned}
$$

where $S$ is the area, $\partial S$ is its piecewise-smooth boundary. All the functions in (15) are supposed to be smooth.

\section{Elastoplastic problem for an arbitrary hole in case when the plastic area surrounds the entire hole}

Assume $C$ is a piecewise-smooth contour, there is a load applied to it

$$
l_{1} \tau^{1}+l_{2} \tau^{2}=\tau_{n}, \quad\left|\tau_{n}\right| \leqslant \sqrt{\frac{l_{1}^{2} a_{23}+l_{2}^{2} a_{13}}{a_{13} a_{23}}}
$$

where $\left(l_{1}, l_{2}\right)$ are normal's vector components to contour $C$. The plastic area's contour $L$ surrounds entirely the hole $C$. See Fig. 1.

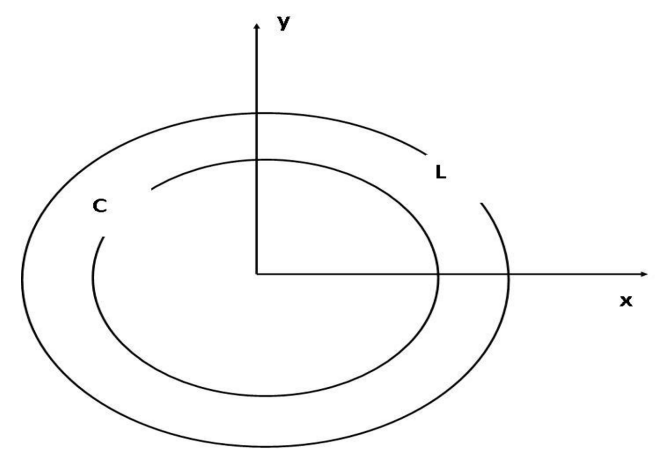

Fig. 1. Elastic-plastic border near the hole $C$

In this case on contour $C$, apart from the condition (16), also fulfilled is the yield condition (7). Thus on $C$ there are two conditions:

$$
l_{1} \tau^{1}+l_{2} \tau^{2}=\tau_{n}=\tau_{n}, \quad a_{13}\left(\tau^{1}\right)^{2}+a_{23}\left(\tau^{2}\right)^{2}=1
$$

From the conditions (17) we find the stress components on contour $C$ :

$$
\tau^{1}=-\frac{l_{2}}{l_{1}} \tau^{2}+\frac{\tau_{n}}{l_{1}}, \quad \tau^{2}=\frac{a_{13} l_{2} \tau_{n} \mp l_{1} \sqrt{l_{1}^{2} a_{23}+l_{2}^{2} a_{13}-a_{13} a_{23} \tau_{n}^{2}}}{l_{1}^{2} a_{23}+l_{2}^{2} a_{13}} .
$$

From this point on, to be definite, in formulas (18) we will be selecting the upper sign.

\section{The use of conservation laws to find stress components in the area}

Assume the point $M\left(x_{m}, y_{m}\right)$ lies beyond the contour $C$. Let us draw a circumference with radius $\varepsilon$ with the centre at the point $M$. We have $\varepsilon:\left(x-x_{m}\right)^{2}+\left(y-y_{m}\right)^{2}=\varepsilon^{2}$. Assume $D$ is 
a line connecting the point $M$ with the contour $C$. We obtain a closed contour consisting of the circumference $\varepsilon$, the segmant $P$ and the contour $C$. See Fig. 2.

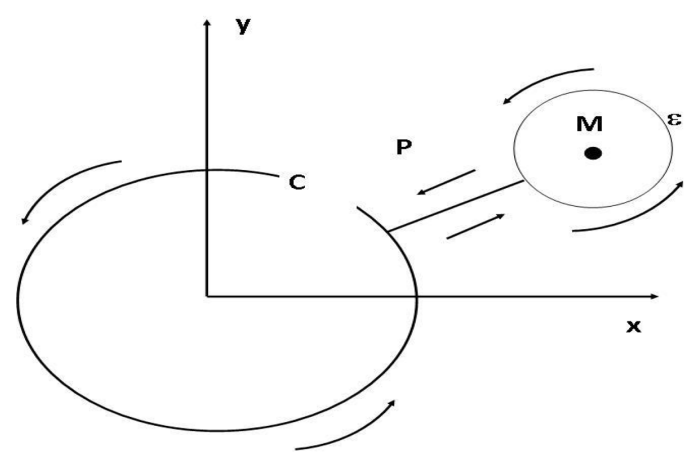

Fig. 2. Calculating the contour integral around the singular point $M$

From (15) we obtain

$$
\oint_{C} A d y-B d x+\int_{P^{+}} A d y-B d x+\int_{P^{-}} A d y-B d x+\oint_{\varepsilon} A d y-B d x=0 .
$$

The sum of the second and the third summands in (19) is equal to zero, because the integrals are calculated in different directions. Finally from (19) we have

$$
\int_{C} A d y-B d x=-\oint_{\varepsilon} A d y-B d x .
$$

Let us convert the right-hand part of equation (20) introducing parametrisation $x=\varepsilon \cos t$, $y=\varepsilon \sin t, 0 \leqslant t \leqslant 2 \pi$. As a result we have

$$
\oint_{\varepsilon} A d y-B d x=\varepsilon \int_{0}^{2 \pi}(A \cos t+B \sin t) d t .
$$

Assume in (15)

$$
\alpha^{1}=\frac{x}{x^{2}+n y^{2}}, \beta^{1}=-\frac{y}{x^{2}+n y^{2}}
$$

Then from (21) we obtain

$$
\oint_{\varepsilon} A_{1} d y-B_{1} d x=\varepsilon \int_{0}^{2 \pi}\left(A_{1} \cos t+B_{1} \sin t\right) d t=\int_{0}^{2 \pi} \tau^{1} d t=2 \pi \tau^{1}\left(x_{m}, y_{m}\right) .
$$

The last equality in (23) is obtained with the use of the mean-value theorem with $\varepsilon$ tending to zero.

Assume in (15)

$$
\alpha^{1}=\frac{\sqrt{n} y}{x^{2}+n y^{2}}, \quad \beta^{1}=\frac{1}{\sqrt{n}} \frac{x}{x^{2}+n y^{2}} .
$$

Then from (21) we obtain

$$
\oint_{\varepsilon} A_{2} d y-B_{2} d x=\varepsilon \int_{0}^{2 \pi}\left(A_{2} \cos t+B_{2} \sin t\right) d t=\int_{0}^{2 \pi} \tau^{2} d t=2 \pi \tau^{2}\left(x_{m}, y_{m}\right) .
$$

The last equality in (25) is obtained with the use of the mean-value theorem with $\varepsilon$ tending to zero. 
From formula (20), and also from (23) and (25) we obtain

$$
\int_{C} A_{1} d y-B_{1} d x=-2 \pi \tau^{1}\left(x_{m}, y_{m}\right), \quad \int_{C} A_{2} d y-B_{2} d x=-2 \pi \tau^{2}\left(x_{m}, y_{m}\right) .
$$

\title{
Conclusion
}

Formulas (26) offer the opportunity to find stress components in any point $x_{m}, y_{m}$ beyond the contour $C$. This allows us to determine the boundary between the elastic and plastic areas. If the plasticity condition is met $a_{13}\left(\tau^{1}\right)^{2}+a_{23}\left(\tau^{2}\right)^{2}=1$ at the point $x_{m}, y_{m}$ then this point belongs to the plastic area, if in the point the condition $a_{13}\left(\tau^{1}\right)^{2}+a_{23}\left(\tau^{2}\right)^{2}<1$ is met, then to the elastic area.

Note. The formulas found above allow us to solve elastoplastic problems even if the plastic contour does not entirely surrounds the contour $C$, provided that on the contour $C$ the plasticity condition (7) is fulfilled.

\section{References}

[1] B.D.Annin, G.P.Cherepanov, Elastic-plastic problem, Novosibirsk, Nauka, 1983 (in Russian).

[2] S.G.Lehnitsky, Theory of elasticity of an anisotropic body, Moscow, Nauka, 1977 (in Russian).

[3] S.I.Senashov, A.M.Vinogradov, Proc. Edinburg Math. Soc., 31(1988), no. 3, 415-439.

DOI: $10.1017 /$ S0013091500006817

[4] P.P.Kiryakov, S.I.Senashov, A.N.Yakhno, Application of symmetries and conservation laws to solving differential equations, Novosibirsk, Ros. Acad. nauk. Sib. otd., 2001 (in Russian).

[5] S.I.Senashov, O.V.Gomonova, A.N.Yakhno, Mathematical problems of two-dimensional equations of ideal plasticity, Krasnoyarsk, Izd. SibGAU, 2012 (in Russian).

\section{Анизотропная антиплоская упругопластическая задача}

Сергей И. Сенашов

Ирина Л. Савостьянова

Сибирский государственный университет науки и технологий им. М. Ф. Решетнева

Красноярск, Российская Федерация

Ольга Н. Черепанова

Сибирский федеральный университет

Красноярск, Российская Федерация

\begin{abstract}
Аннотация. В работе решена анизотропная антиплоская упругопластическая задача о напряженном состоянии в теле, ослабленном отверстием, ограниченном кусочно-гладким контуром. В статье приведены законы сохранения, которые позволили свести вычисления компонент тензора напряжений к криволинейному интегралу по контуру отверстия. Законы сохранения дали возможность найти границу между упругой и пластической областями.
\end{abstract}

Ключевые слова: анизотропная упругопластическая задача, антиплоское напряженное состояние, законы сохранения. 